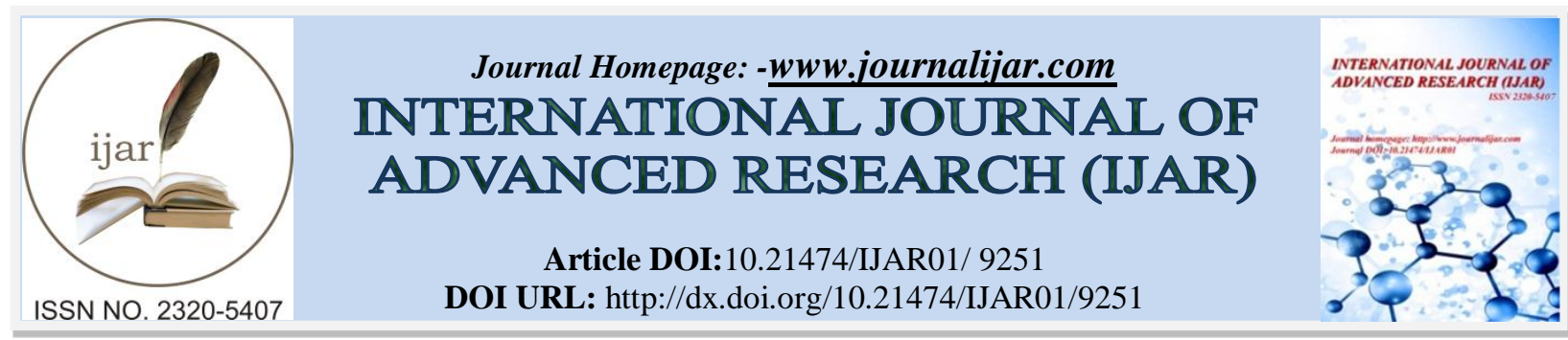

RESEARCH ARTICLE

\title{
H. PYLORI GASTRITIS IN PATIENT WITH ACTIVE DUODENAL ULCER IN AL-YARMUK HOSPITAL.
}

\section{Dr. Asaad. M. Sadik ${ }^{1}$ and Dr. Hussein Alhilli ${ }^{2}$.}

1. M.B.Ch.B, DM Medicine specialist at Al-Nuaman Hospital.

2. M.B.Ch.B, MRCP, Professor in internal medicine, Al-Mustansyriah College of Medicine.

\section{Manuscript Info}

Manuscript History

Received: 10 April 2019

Final Accepted: 12 May 2019

Published: June 2019

Key words:-

Gastritis, H. pylori, duodenal ulcer, endoscopy

\section{Abstract}

Background: It is estimated that $50 \%$ of the world's population is infected by $\mathrm{H}$ pylori. It is isolated from the antrum of patient with active chronic gastritis, the organism has been demonstrated in the antrum in most patient with duodenal ulcer.

Methods: Twenty eight randomly selected patients were found to have active duodenal ulcer as diagnosed by endoscopy in the endoscopy department of Al Yarmuk teaching hospital.

Results: All the patients in the study were found to have histological gastritis, twenty one (75\%) were found to have H. pylori organism diagnosed by direct staining method of the histological specimen, sixteen $(57 \%)$ were found to be positive in special culture media for $\mathrm{H}$. pylori.

Conclusion: there is high prevalence of $\mathrm{H}$. pylori gastritis in Iraqi patient with active duodenal ulcer

Copy Right, IJAR, 2019,. All rights reserved.

\section{Introduction:-}

It is estimated that $50 \%$ of the world's population is infected by $\mathrm{H}$. pylori ${ }^{(1)}$. Although most infections are not associated with clinical disease, a significant proportion will go on to develop some of the commonest problems in gastroenterology: gastritis, peptic ulcer disease, and gastric cancer ${ }^{(2)}$. Low education levels have also been positively associated with H. pylori infection in several studies ${ }^{(3)}$.

Chronic antral gastritis has been described in most of patient with duodenal ulcer disease, the significance of this gastritis is unknown, it is suggested that it reflect a base underlying abnormality common to both duodenal and gastric ulcer and that both diseases are simply different point in a continuous spectrum ${ }^{(4)(5)}$. In 1983 Marshal described the isolation of $\mathrm{H}$. pylori from the antrum of patient with active chronic gastritis and since that time the organism has been demonstrated in the antrum in most patient with duodenal ulcer ${ }^{(6)}$. The presence of $\mathrm{H}$. pylori has been correlated closely with histological lesion and it is suggesting that $\mathrm{H}$. pylori is the aetiological agent of this gastritis ${ }^{(7)}$. H. pylori is a small curved or spiral shaped gram negative bacillus that is found beneath the mucous gel of the human stomach, it has been isolated from only two region of the human gastrointestinal tract, the stomach and the duodenal bulb, in the stomach it may be detected throughout the fundus, body and the antrum ${ }^{(8)}$. 
H. pylori is usually sensitive to a large number of antibiotics these include Penicillin, Ampicillin, Amoxycillin, Erythromycin, Cephalosporine, Tetracyclin, Gentamycin and Kanamycin and Colloidal Bismuth substrate, one evidence for $\mathrm{H}$. pylori playing a causal role in gastritis that eradication of $\mathrm{H}$. pylori from the gastric mucosa result in improvement or even resolution of gastritis ${ }^{(9)}$.

H. pylori infection is recognized as a significant public health problem in developing countries. Both antibiotic resistance and re-infection rates threaten the efficacy of existing eradication therapy ${ }^{(10)}$.

Triple treatment including proton pump inhibitor, amoxicillin and clarithromycin or metronidazole proposed at the first Maastricht conference is globally accepted as the technique used to treat H. pylori infection. However, recent data show that efficacy of this combination has decreased, with successful cure in only $70 \%$ patients ${ }^{(11)}$.

The relation of $\mathrm{H}$. pylori infect in the pathogenesis of duodenal ulcer is not conclusive, there are studies which suggest causal relation, however there is very clear evidence that irradication of $\mathrm{H}$. pylori is not necessary for ulcer healing as in case of $\mathrm{H}_{2}$ receptor blocker treatment which cause healing in those who remain $\mathrm{H}$. pylori positive ${ }^{(12)}$.

\section{Aim of the study:}

To find out the prevalence of H. pylori gastritis in Iraqi patient with active duodenal ulcer.

\section{Patients and methods:-}

Twenty eight randomly selected patient were found to have active duodenal ulcer as diagnosed by endoscopy in the endoscopy department of Al Yarmuk teaching hospital, the source of patient examined were either inpatient or outpatient, the endoscopy used was olympus g1Fp3 type, patient were inquired about recent use of any antibiotic and antiulcer treatment, the evidence of antral gastritis, were looked for then biopsy specimens were taken from the antrum within 3-5 cm from the pyloric region, two specimens were sent for microbiological study (direct \& culture), and one specimen were sent for histopathological study, the endoscopy sterilized with Hibitane and the biopsy forceps were sterilized with sprit prior to each endoscopy examination, specimen for microbiological study were put in $0.5 \mathrm{ml}$ of $20 \%$ glucose solution which was add to $1 \mathrm{ml}$ brain-heart infusion in sterile test tube used as transport medium, biopsy specimen for histological study was fixed in natural buffered formalin and processed routinely, section were stained with Haematoxylin and Eosin $(\mathrm{H} \& \mathrm{E})$, the severity of histological gastritis was graded on the base of inflammatory cell infiltration in the lamina propria as follow:

Grade 0: normal antral mucosa

Grade 1: mucosa with only mild increase in mononuclear cell but otherwise with normal limit and showing no other evidence of inflammation.

Grade 2: mucosa with expansion of the lamina propria by increase number of mononuclear cells.

Grade 3: mucosa demonstrating the feature of grade 2 with the addition of an acute inflammatory cell infiltrate (active chronic gastritis) grading for the purpose of this study were based solely on the inflammatory cell infiltrate.

The specimen was also stained with gram stain and H\&E stain to detect the presence or absence of gram negative organism on the surface epithelium, these section were graded as positive or negative for $\mathrm{H}$. pylori but no quantitative assessment was made.

\section{Results:}

Gastritis were detected by endoscopy performed to all patients.

Histopathological results: Antral gastritis was found in all (100\%) of the cases, there were 4 cases (14\%) in grade 1 gastritis, 10 cases (35\%) in grade 2 gastritis, 14 cases $(50 \%)$ in grade 3. H. pylori was detected in $21(75 \%)$ out of 28 cases, there were 2 out of 4 cases in grade 1,7 out of 10 in grade 2 , and out of 14 in grade 3 , H. pylori was not detected in 7 cases only. This relationship between H. pylori status and grades of histological gastritis were shown in table 1 .

Table 1:-The relationship between H. pylori status and grades of histological gastritis

\begin{tabular}{|c|c|c|c|c|c|c|c|}
\hline \multirow[b]{3}{*}{ Gastritis } & \multicolumn{6}{|c|}{ H. pylori growth } & \multirow{3}{*}{$\begin{array}{c}\text { Chi-sq test } \\
\text { P-value }\end{array}$} \\
\hline & \multicolumn{2}{|c|}{ Positive } & \multicolumn{2}{|c|}{ Negative } & \multicolumn{2}{|c|}{ Total } & \\
\hline & No. & $\%$ & No. & $\%$ & No. & $\%$ & \\
\hline Grade 1 & 2 & $50 \%$ & 2 & $50 \%$ & 4 & $14 \%$ & \\
\hline Grade 2 & 7 & $70 \%$ & 3 & $30 \%$ & 10 & $35 \%$ & $\begin{array}{l}2.324 \\
0.313\end{array}$ \\
\hline Grade 3 & 12 & $86 \%$ & 2 & $14 \%$ & 14 & $50 \%$ & \\
\hline
\end{tabular}




\begin{tabular}{|l|l|l|l|l|l|l|} 
Total & 21 & $75 \%$ & 7 & $25 \%$ & 28 & $100 \%$ \\
\hline
\end{tabular}

Microbiological results: out of 28 biopsy specimens submitted to culture there were 16 (57\%) specimen positive for H. pylori and $9(32 \%)$ shows growth of monilia, the last $3(10 \%)$ showed unidentified growth consider as contaminant, these are represented in table 2.

Table 2:- microbiological growth obtained from the biopsies

\begin{tabular}{|l|c|c|}
\hline Type of growth & No. & $\%$ \\
\hline H. pylori & 16 & 57 \\
\hline Monilia & 9 & 32 \\
\hline Unidentified growth & 3 & 10 \\
\hline
\end{tabular}

\section{Discussion:-}

The high frequency of histologically proven gastritis in patient with active duodenal ulcer as diagnosed by endoscopy is now recorded in many country as was shown in studies done in Ireland (78\%) ${ }^{(4)}$, Brazil (78\%) ${ }^{(7)}$, in England $(94 \%)^{(9)}$, in our finding the prevalence of histologically proven gastritis in patient with active duodenal ulcer was $(100 \%)$ which is higher than what was found in other studies we also found that endoscopic appearance was unreliable indicator of histologically proven gastritis, gastritis was diagnosed endoscopically in only (32\%) of patient with histologically proven gastritis. H. pylori infection of patient with duodenal ulcer as shown in studies done Ireland $(90 \%)^{(4)}$, Brazil $(78 \%)^{(7)}$, Amsterdam $(98 \%)^{(12)}$, our study only 16 patients $(57 \%)$ was culture positive for H. pylori, however we have recognized there have been technical fault in preparation of transport and culture media in the beginning of the study, nevertheless $H$. pylori was detected by direct staining method of the histopathological specimen in 21 patients $(75 \%)$.

In conclusion there is high prevalence of $\mathrm{H}$. pylori gastritis in Iraqi patient with active duodenal ulcer, however this study needs to be extended to involve more patients and to recognize the true prevalence of positive $\mathrm{H}$. pylori culture for gastric mucosa.

\section{References:-}

1. Torres J, Pérez-Pérez G, Goodman KJ, Atherton JC, Gold BD, Harris PR, et al. (2000). A comprehensive review of the natural history of Helicobacter pylori infection in children. Arch Med Res; 31:431-69.

2. Suerbaum S, Michetti P. Helicobacter pylori infection. (2002). N Engl J Med; 347:1175-86.

3. Torres J, Leal-Herrera Y, Perez-Perez G, Gomez A, Camorlinga-Ponce M, Cedillo-Rivera R, (1998). A community-based seroepidemiologic study of Helicobacter pylori infection in Mexico. J Infect Dis.;178:108994.

4. Dooley CP, Mckenna D, Humphreys H, Bourke S, Keane CT, Eamonn Sweeney E. (1988). Histological gastritis in duodenal ulcer: relationship to campylobacter pylori and effect of ulcer therapy. The American Journal of gastroentroenterology. 83(3):

5. Piper DW., (1988). Peptic ulceration. Baillieres clinical gastroenterology; 2: 3.

6. Marshal BJ, Warcn JR. (1984). Unidentified curved bacilli in the stomach of patient with gastritis and peptic ulcer. Lancet, 1-1311.

7. Coelho LG, Das SS, Karim QN, Walker MM, Queiroz DM, Mendes EN, et al. (1987). Campylobacter-pyloridis in the upper Gastrointestinal Tract: A Brazilian study. Arg Gastroenterol, 24 (1): 5-9.

8. Dubois A. (1995). Spiral Bacteria in the Human Stomach: The Gastric Helicobacters. Center of diseases control and prevention. 1(3):

9. Earlam RJ, Jamerigo, Kakavoulis T, Pollok DJ. (1985). Histopathological appearance of oesophagus, antrum and duodenum and their correlation with symptoms in patient with a duodenal ulcer- GUT; 26, 95-100.

10. Mandeville KL, Krabshuis J, Ladep NG, Mulder CJ, Quigley EM, and Khan SA. (2009). Gastroenterology in developing countries: Issues and advances. World J Gastroenterol. 21; 15(23): 2839-54. doi: 10.3748/wjg. 15.2839

11. Nishizawa T and Suzuki H. (2014). Mechanisms of Helicobacter pylori antibiotic resistance and molecular testing. Front Mol Biosci. 1: 19 doi: 10.3389/fmolb.2014.00019

12. Rauws EA, Langenberg RW, Houthoff HJ, Zanen HC, Tytgat GJ. (1988). Campylobacter pyloridis-associated chronic active antral gastritis. A prospective study of its prevalence and the effects of antibacterial and antiulcer treatment. Gastroenterology; 94(1): 33-40. 